\title{
RE-PRESENTING URBAN ABORIGINAL IDENTITIES: SELF-REPRESENTATION in CHILDREN of the SUN
}

\section{BRONWYN LUMBY 1 \& COLLEEN MㄷLOIN ${ }^{2}$}

1 Jumbunna Indigenous House of Learning, University of Technology, Sydney, PO Box 123, Broadway, New South Wales, 2007, Australia

2 Woolyungah Indigenous Centre, University of Wollongong, Northfields Avenue, Wollongong, New South Wales, 2522, Australia

\section{溜 Abstract}

Teaching Aboriginal studies to a diverse student cohort presents challenges in the pursuit of developing a critical pedagogy. In this paper, we present Cbildren of the Sun (2006), a local film made by Indigenous youth in the lllawarra region south of Sydney, New South Wales. We outline the film's genesis and its utilisation in our praxis. The film is a useful resource in the teaching of urban Aboriginal identity to primarily non Indigenous students in the discipline of Aboriginal studies. It contributes to the development of critical thinking, and our own critical practice as educators and offers a starting point to address pre-conceived and stereotypical notions about race and colour. We situate this paper within a theoretical framework of identity and whiteness studies to explore the issue of light skin in relation to the constraints of identity surrounding urban Aboriginal youth, as represented in Children of the Sun. We discuss the usefulness of this film as a self-representational text that subverts and challenges pre-conceived notions of Aboriginal identity
Introduction

Urban Aboriginal identity in Australia, although inspiring an emerging academic interest, is still largely an under-researched field of study. Finding appropriate tools to teach students about the concept of urban Australian Aboriginality, in its many and varied contexts, and particularly at a local level, is a continual challenge. In out experience as university teachers teaching Aboriginal studies to a culturally diverse cohort of undergraduate students, we have come to realise that Aboriginal identity (invariably defined in popular culture texts through the lens of traditional Aboriginal culture), is still very much embedded in "knowledge" of Aboriginal people circulated from both outside, and indeed, from within many parts of the academy, that is based on a fantasy of tradition. This perspective often has no point of connection for contemporary urban Indigenous people. Many literary and feature film representations of Aboriginal people used in undergraduate teaching refer to Aboriginal histories, but fail to make connections with many contemporary, Indigenous struggles in an urban context. Although knowledge of history is crucial in tracing and understanding the trajectories of Aboriginal identities, we find there is a paucity of useful material that focuses specifically on contemporary sites where urban Aboriginal identities are formed and transformed, and where agency is foregrounded in the process of acquiring, creating, and performing identities. Various standpoints on identity are therefore presented in our teaching. For example, Martin Nakata's (2007, pp. 195-212) theory of the "cultural interface" is useful when thinking about the production of Indigenous identities. Referring to Torres Strait Islander peoples' histories and experiences of colonial rule, Nakata sees the "cultural interface" as a site of struggle where Indigenous people are in a state of constant negotiation with dominant discourses of race and identity, and where Indigenous subjects assert agency in the reforming of identities that reflect experience and everyday life. Stuart Hall's work on identity is also helpful. He reminds us that:

perhaps instead of thinking of identity as an already accomplished historical fact, which the new cinematic discourses then represent, we 
should think, instead, of identity as a production, which is never complete, always in process and always constituted within, not outside, representation (cited in Davis, 2004, p. 184).

Hall's work can be a valuable starting point to engage students in ideas of how representation works semiotically to construct identities, while Nakata's work provides a specific colonial context that can be used to examine the historical conditions of colonialism, and the ideologies that continue to inform representations of Indigeneity.

\section{Developing a critical pedagogy in Indigenous studies}

It is appropriate to locate our own identities as educators and writers; Bronwyn Lumby is Indigenous and Colleen McGloin is non-Indigenous (British migrant). We collaborate both as colleagues and friends and find a common interest in our teaching through our mutual interest in racial, cultural and national identities which we come to from different cultural standpoints, and also, from different academic disciplinary foci: Bronwyn Lumby from sociology and Colleen McGloin from cultural studies. We are also informed in our approach to teaching and learning by the politics of feminism which provides us with ways of understanding and teaching the untidy intersections between racial, gendered and sexual identities that accrue around issues of Aboriginal identity. We teach Aboriginal studies to a culturally diverse and largely non-Indigenous student body. Indeed, most of our first year students are Study Abroad students from the United States whose knowledge of the history of colonialism in Australia is understandably sparse. Aboriginal studies also attracts students from Japan, Korea, and various European countries, as well as domestic, non-Indigenous Australian students. Indigenous students comprise approximately $5 \%$ of our cohort, and it is these students who are the focus of the teaching Unit's endeavours in terms of recruitment and providing Indigenous students with access to a well-supported experience of higher education. Currently, as Nakata notes, "the establishment of the enclave system, which supports Aboriginal and Torres Strait Islander education in universities is a powerful and effective mechanism ... but it is not sufficient" $(2004$, p. 2). In our efforts to develop a critical antiracist pedagogy, we are faced with the challenging, and yet often invigorating task of "pitching" our teaching towards the goal of engendering critical inquiry for all students interested in learning about Indigenous issues, while considering specifically the needs of Indigenous students which often differ from those of non-Indigenous students. In other words, we attempt to ensure that theory and practice are not separated, but reflect the interests of the students whose histories we teach. In particular, our goal is to embed texts and practices into a pedagogy that reflects and foregrounds Indigenous experience and knowledge, and illustrates cultural difference in visually accessible formats. The potential for film as a visual medium that marks physicality, as in many cases it obscures cultural identity, provides us with points of reference that are useful in teasing out the cross-points of cultural connectivity - or disconnectedness.

In aiming to understand precisely what constitutes critical pedagogy in Indigenous education, it is important for us to be clear about what it is we are trying to achieve. Critical pedagogy can be described broadly as a vehicle for social change (see the work of Freire, hooks, Giroux, Aronowitz), but specifically in the case of Aboriginal studies in Australia, it is primarily concerned with developing, in students and educators, an understanding of, and political response to, the on-going violence of colonial history. We see critical pedagogy developing through teaching and learning that politicises and makes comprehensible everyday experience by investing it with meaning. This involves a process of helping students understand their own subjectivity, so that they can see their relationship to the world. In teaching anti-racism, we have found that critical thinking about issues of race is often generated when students initially focus their inquiries on themselves. In other words, we contend that students need to be self-reflexive about their own position in order to think critically about the position of others. This process is often steered towards questions about identity (e.g., who "we" are, how do we come to perceive others, and how and where do ideas about other cultures circulate). We often begin generally from the standpoint that identities are formulated through a set of discursive practices and texts that circulate in culture.

We frequently invite students to discuss their favourite texts, which for the most part, are televisual. It is from such discussions that we are able to start raising broad questions, to pinpoint and to counter some of the ways representations of nation, culture and the body politic, naturalise whiteness as a signifier that seemingly "just is", as Moreton-Robinson argues, a "normative" construct that seemingly disconnects epistemology from whiteness (MoretonRobinson, 2004, p. 87). We then discuss identities in their various states of process or becoming, inviting consideration of how identities can be conceived and produced through cultural agents who actively contest, through the means of cultural production and consumption, stereotypical representations of Aboriginality. We raise questions about how, in the face of colonial dislocation, Aboriginal identities are constructed, realised, performed and imagined through the dominant, yet seemingly invisible lens of white privilege, what Bhabha calls the "tyranny of the transparent" (Bhabha, 1998, p. 1). Our aim in developing a critical praxis is to give students the skills 
to denaturalise this transparency so that other ways of thinking and knowing can become possible.

Many of our classes include light-skinned Aboriginal students who may or may not identify openly as Aboriginal. In cases where Aboriginal students elect to identify, it is common for the majority non-Aboriginal student cohort to position them as "experts", a situation that can produce overwhelming anxiety, especially for students who have recently discovered their Aboriginal heritage and are keen to study and understand their cultural heritage from the perspective of their own history and experiences. The imposition of the "expert" status can have a significant pedagogical effect both through the presumption of knowledge that may or may not be in place, but also, we are mindful that Aboriginal students are often reluctant to "take the stage" precisely because they are themselves engaged in a process of learning, and indeed often, of becoming. The most crucial factor, we feel, in the development of a critical pedagogy that can actually effect change, is a strong adherence to open dialogue combined with an approach that allows the students to know $u s$ as women of different cultures who have a strong commitment to Indigenous education. So, we aim, carefully at times, to break down the barriers of what can and cannot be said, in order to stimulate inquiry and generate debate, as hooks notes, "[T]o engage in dialogue is one of the simplest ways we can begin as teachers, scholars, and critical thinkers, to cross boundaries ..." (hooks, 1994, p. 130).

Crossing boundaries is at the core of Aboriginal studies. Teaching mainly white non-Indigenous students, we have found a consistent tendency to make invisible Indigenous students, or persons, based on often iterated statements such as, "I don't know any Aboriginal people" or "there are no Aboriginal people in this class". Aboriginality, then, becomes only identifiable through a visibility that is acceptable to, or recognisable by, non-Aboriginal students, and in the case of the latter statement which has often been a false assumption, there is a process of silencing that adversely affects the teaching and learning of Aboriginal students. To borrow from Maureen Perkins, "for some fair-skinned people who identify as black or of colour, their 'white' appearance may be a difficulty, since their cultural belonging may be constantly misread by both strangers and members of their own community" (Perkins, 2004, p. 165). The postcolonial construct of Indigeneity according to certain pre-ordained criteria is fraught with complexity and contention. Kevin Gilbert asserts that there is no distinctive Aboriginal identity and that Aboriginal people are connected by "their black skin, their poverty, and their shared experiences of persecution and horror" (Gilbert, 2002, p. 179). Although this viewpoint provides students with a historical context, we have found that some Aboriginal students do not relate to the disadvantage $=$ Aboriginality formula.
It is these very complex and contradictory issues surrounding specifically contemporary urban Indigenous youth that structure the content of a 200 Level subject we co-teach. And in trying to teach critical analysis of these issues, we find visual material can offer stimulus to questions raised by many urban Indigenous youth affected by the legacy of assimilation policies, such as "who am I?" or "how do I identify?" or "where do I fit in?" Such questions are often left out of representations, sidelined, or embedded in historical explanations without acknowledgement of the part played by Indigenous youth in producing and negotiating identities themselves by interacting with existing texts to make sense of their place in the world. This is not to suggest that there is no useful material available; we have found short films by internationally acclaimed Indigenous filmmakers such as Wayne Blair and Warwick Thornton for example, invaluable in explaining the effects of history on emerging identities and have incorporated many short films into our teaching. As Nakata states of Indigenous students,

in studying the texts that have been written about them, scholars are negotiating with representations of themselves, their ancestors and their experience. [This] is not simply an intellectual process. It is an emotional journey that often involves outrage, pain, anger, humiliation, guilt, anxiety and depression (1998, p. 4).

Children of the Sun (2006) attempts to address some of these issues.

Cbildren of the Sun is a self-representational short film that addresses Indigenous students. It foregrounds their struggles with identity, and challenges some of the stereotypical assumptions and expectations of our majority non-Indigenous student body. The film explores the issue of how urban Aboriginal identities are formed in contemporary 21 st century Australia at a local level. It raises questions such as, what kinds of negotiations take place in the process of identity formation? What subject positions are available for Indigenous youth? What happens when the tools of representational procluction are in the hands of Indigenous youth themselves? The film also encourages students to consider how representations of Indigenous people made by Indigenous people can effect a transformation in subjectivity for Aboriginal youth. It also raises questions for nonIndigenous students about the process and politics of representation per se.

Children of the Sun: Genesis and thematic approach to urban Aboriginal youth identities

This intense questioning of authenticity, which can hit you with the force of a sledgehammer, 
is due to the profound disruption that whiteskinned Indigenes represent for the Black-White racial dichotomy, so fervently clung to in Australia. As one person put it, "sometimes ... it would be just a lot easier to say I'm not Aboriginal" (Boladeras, 2002, p. 116).

Children of the Sun is a 28 minute short film by the Koori Youth Network (KYN) a youth group founded in 2004 by Bronwyn Lumby and based in the lllawarra, south of Sydney. KYN's purpose is to provide a forum for its members to have a say in the development of programs for Aboriginal youth. After successfully tendering for funding from the Foundation for Young Australians, KYN grew and took a direction of its own, and eventually moved towards being a support group which aimed to encourage education and cultural pride. The production of Children of the Sun is one of many achievements supported and endorsed both from within, and outside of the local community. The film was screened in the New South Wales State Parliament at the invitation of the Minister of Aboriginal Affairs in 2006. Conceptualised, written and produced by the actors and their mentors in 2006 , the film was shot both at Mount Keira in Wollongong, the site of a significant Dreaming story for local Aboriginal people, and in various areas of Sydney's National Park. Those involved in the project were presented with certificates of encouragement for their work in the film by internationally acclaimed cinematographer Warwick Thornton. Following its launch, the film was also screened in several cities in New South Wales as part of the NAIDOC (National Aboriginal and Islander Day of Observance Committee) celebrations. Children of the Sun is unique in that it addresses the issue of urban Australian Aboriginality from the perspective of local Indigenous youth whose input into the dialogue and suggestions for the film's development and narrative structure demonstrate the power of agency in representation, and its capacity to make new spaces available for formulating identities. While a fictional text, the film engages directly with the effects of colonial history on contemporary Aboriginal youth. It connects past practices to contemporary issues and the struggles experienced by many local Indigenous youth in their attempts to know and understand who they are, and to have an active role in deciding who they can be.

Children of the Sun was inspired by an interest in issues of Aboriginal identity and by observations of the ways in which Aboriginal youth can be seen to actively construct identity through dialogue, interaction, cultural practices, and through engaging with, or subverting, existing texts and practices that proclaim what Aboriginality can, or should be. Initial discussions with members of the KYN were based on what kind of a project would be enjoyable, educational, and would address the many issues raised by Indigenous youth, particularly those relating to identity. A short film, it seemed, would be the perfect vehicle to capture the diverse points of view and subject positions that formulate emerging Aboriginal identities in the local context. The film's main exploratory theme is the issue of colour as this relates to Aboriginality. It asks what are the difficulties for light-skinned Aboriginal people when choosing to identify if skin colour and physicality are "exceptionally important in the recognition and validation of Aboriginal identity" (Boladeras, 2002, p. 147). The film echoes the participants' questions and concerns about colour and culture. More importantly, though, it provides a discursive arena of production where urban Aboriginal kids, particularly those with light skin, can explore the possibilities for identity and begin to "undo" the mythology of colour that has historically decreed what Aboriginality is, can, or should be. In other words, it explores the connection between whiteness as a signifier for Aboriginality, and knowledge production. In the initial planning stages, discussions wete open, invigorating, and interesting. Many of the darker-skinned kids spoke of the constant barrage of racist taunts and abuse they are subject to in public places and at school, while lighter-skinned participants relayed the continual battle they face to acquire acceptance and recognition both from the Aboriginal community, and from without, because their skin colour does not conform to dominant discourses of what constitutes Aboriginality. The policing of identity, from within or outside of community serves to alienate, and force lighter-skinned subjects who identify into a "prison-house" of identity (Ang, 2001, p. 11).

\section{Narrative synopsis and analysis}

Cbildren of the Sun addresses these tensions through the narrative's focus on the central character, Kia Bennett, a 16 year-old light-skinned Aboriginal girl who is struggling with her identity and pressured by her non-Aboriginal female friends to "pass": "You are one of the lucky ones Kia ... You can hide it. You don't have to be one of them ... You shouldn't be forced to be somebody that you don't want to be". The assumption that Kia doesn't "want to be" Aboriginal suggests a normative desire to be white, and to identify with white culture. Inbuilt into this statement is the acknowledgment that being Aboriginal incurs regulative control, and that being "lucky" will bring the rewards and privileges enjoyed by white subjects, as Moreton-Robinson notes, the invisibility of whiteness secures its hegemony (2004, p. 75). Kia's journey of identity is complicated by the insertion of a romance with a dark-skinned Aboriginal youth who understands and engages with Kia's search for identity, and who Kia's friends see as a threat to her being able to "pass" as white. The narrative follows Kia's struggle with who she is, the affirmations of her 'whiteness' 
from her non-Aboriginal friends, and the attempts by her culturally proud boyfriend, Joshua, and members of her community to reinforce her Aboriginal cultural identity. The opening scene depicts Kia standing on a cliff overlooking a vast landscape of bush and ocean on the Illawarra coast. This scene unequivocally alerts the viewer that this is a story about the struggle for identity Kia states, "I am Kia Bennett. I am 16 years old. I am a Nukunu girl. I am Aboriginal" ("Nukunu" refers to an Aboriginal clan located around the Port Pirie area in South Australia). It is the notion of what Aboriginality looks like, or should look like, that is explored, not only in terms of visuality, but also in a broader context the film asks what is it to be Aboriginal, and how is Aboriginality expressed, lived and experienced by light-skinned Aboriginal youth who are products of enforced miscegenation and assimilation policies. The film encourages viewers to consider the available subject positions for visually un-identifiable Aboriginal youth within dominant discourses, and to understand how subject positions are actively re-created to fit with corporeality and the practices of daily life, and to assert cultural identity.

In early discussions in the filmmaking process, the notion of "passing" was frequently alluded to by those who were light-skinned, and the inclusion of dialogue expressing anxiety about this issue gave voice to frames of reference that for many had not been previously articulated. Passing raised pertinent questions: What are the consequences of passing as white? What are the repercussions of not passing? What happens when someone can pass, and refuses to? What happens when someone chooses to pass? Most importantly, though, the film acts as a stimulus to critical practice by raising the question: how does whiteness as a corporeal marker maintain its structural authority and dominance? $\mathrm{Kia}$ is warned by her nonIndigenous friend, Danielle, of the cost of being able to pass, and yet choosing to identify as Aboriginal "if you identify as Aboriginal you will never be given a chance, never a second look. I am not a racist Kia ... I am a realist". Kia is left in doubt as to the consequences of not passing as white. The simplistic conflation of being non-racist and realistic situates the dialogue within a recognisable framework or racist strategy that iterates white epistemologies of rationality as just being so, seemingly without ideological underpinnings or ethical explanations. It formulates an equation that operates from within the discourse of common sense and as such, constitutes an utterance within dominant discourse that requires no explication. Kia's struggle is most clearly articulated when she declares, "My Mum is an Aboriginal ... I don't look Aboriginal. I don't feel Aboriginal. Shit. What does that even mean?" As it follows Kia's difficulties with identity, the film articulates colonial violence through intermittent appearances of the character, Aunty, whose presence is strategically inserted to narrate the repercussions of assimilation policies that instigated the removal of tens of thousands of Aboriginal children from their families and country, now formally acknowledged as the Stolen Generations. Aunty tells of the policies and their devastating effects on families, kinship relations, and culture. She dismisses outright the misguided efforts of Christian missionaries, openly scorning the efforts of Christians in a disdainful tirade as she recalls the effects of mission life on many Indigenous children. As an elder, Aunty represents the continuity of Indigenous knowledge and the passing down of histories through oral means. She represents resistance to colonial rule, and it's imposed ways of knowing and being.

Kia's struggle for identity reaches a climax when her non-Indigenous friends plot and succeed in brutally slaying her boyfriend, Joshua, ostensibly to "protect" her from his influence, viewed as threatening to her possibilities for passing as white. This moment in the film represents a dramatic simulation of colonial violence. As a scene in a contemporary text, it re-situates colonial violence in the present, refuting the idea that colonial dominance is a thing of the past. The killing of Joshua also reminds viewers of the repercussions of resistance, and the agency of asserting cultural identity. In its reproduction of colonial violence, this scene also elucidates the discursive construction of whiteness that on a national level informed the design and implementation of official assimilation policies whose legacy continues to adversely affect the lives and identities of contemporary Indigenous youth.

Children of the Sun demonstrates the internalisation of oppression which functions not only to complicate issues of identity, but also to regulate and enforce what are considered more acceptable ways of identifying as Aboriginal. The proposition that Kia can only maintain her non-Indigenous friendships if she identifies as white positions her as potentially compliant in acts of cultural oppression through the suggestion she must acquiesce to the regulative forces that seek to outlaw her Aboriginality. That the $\mathrm{KYN}$ actors recognise the codes of acceptable behaviour and their cultural capital in the act of assuming whiteness says much about their knowledge of dominant discourses, and their struggles at the "cultural interface". The film seeks to interrogate the act of seeing race as untenable by questioning the notion that Kia's Aboriginality can be safely secreted or erased at will, and subverting the proposition that race is a matter of physicality rather than cultural and ancestral association.

The film thus plays with the colonial trope of colour as a marker of race, a still pervasive idea familiar to many light-skinned Aboriginal people whose "lack" of colour can exclude them from Aboriginal communities as well as from mainstream recognition of their identity. It is this exclusion that many of the participants identified as central to their daily lives at school, in their communities, and within the broader white Australian community. It is the case that for many Indigenous 
subjects, a repercussion of not being "black enough" is often accompanied by a demand for authentication through documented proof of Aboriginality. The "Proof of Aboriginality" documentation is a requirement made by Aboriginal communities in many regional and rural areas. As a testimonial to self-regulation, it is documented evidence to an individual's authenticity as an Aboriginal person, and while serving some useful purpose in relation to resources and funding accessibility, can also inject anxiety into those who cannot provide proof of their cultural heritage due to skin colour, dislocation, familial fracturing and the continuing effects of past practices. Being "not black enough" is a conflict that for many youth seems an overwhelming hindrance in the search for cultural affirmation; the racial ordering of bodies is invariably inscribed with colour as a dominant feature and the destabilising of racial hierarchies requires discursive knowledge not always available to urban Indigenous youth. It is with this in mind that we aim to embed into our pedagogy some of the theoretical approaches to whiteness that facilitate an understanding of its construction, or underpinning epistemology in the West, and its mechanisms of operation that find expression in representation.

For many urban youth who identify as Aboriginal, knowledge about their Aboriginality, and Aboriginal culture, comes not only through their families but also from school, media texts, social attitudes, and dominant discourses that circulate about Aboriginal people and continue to mark Aboriginality in constricted, and specific ways. For example, in the recent formal public apology to Aboriginal people by the newly-elected Labor Prime Minister, Kevin Rudd, which was warmly received by many Aboriginal people, it is to be noted that no mention is made of urban Aboriginal people's heritage: despite reference to the Stolen Generations, which was largely a practice perpetrated in urban and rural regions, the focus is on traditional identity:

In making this apology, I would also like to speak personally to the members of the stolen generations and their families: to those here today, so many of you; to those listening across the nation-from Yuendumu, in the central west of the Northern Territory, to Yabara, in North Queensland, and to Pitjantjatjara in South Australia (Rudd, 2008).

Identity is a thus discursive construction. It is a process of self-identification based in part on available images and representations that circulate through popular culture, texts such as legal and medical documents, literature, art, and familial oral stories that tell Aboriginal people what and who we are through the passing on of personal histories. In the case of Aboriginal identity, nonAboriginal cultures have historically identified
Aboriginal people through skin colour. Where that raised a "problem" (for non-Indigenous people), the implementation of policies of miscegenation and child removal functioned to produce thousands of visually unidentifiable Aboriginal people. Ironically, this also causes a "problem" in contemporary time as it upsets non-Indigenous categories of identification. Dominant discourses of Aboriginality, therefore, as testified by the above official apology, often elide reference to urban Aboriginal people, focusing on what are perceived as "authentic" Aboriginalities based on traditional cultures where visible signs of cultural definition can be safely categorised and seen. Destabilising these "authentic" categories carries consequences, as Mandawuy Yunupingu notes, "I know from experience that when you upset white people's categories you'd better watch out" (1994, p. 5). Many of Children of the Sun's participants testify to the repercussions of upsetting categories of identification. As the film suggests, for people who identify as Aboriginal, the internalising of the importance of identifiable physical markers incites disputes about who can claim Aboriginality, both from within Aboriginal communities where identity regulation is enforced through the absorption of colonial discourses, and from outside.

Aboriginal people are consistently questioned about Aboriginal identity and included or excluded from communities based on what are often judged to be fraught connections to Aboriginal status, based primarily around issues of physicality. In exploring this issue, the film raises the important question of what constitutes cultural identity and contests the notion that this can be located through physical markers. It does not address the issue of whether or not all visibly Aboriginal subjects must identify as Aboriginal; in a short film, there are limitations to what can be addressed. However, the film explores notions of common historical origins, of community, and of the constant tensions experienced at the "cultural interface". The film's potential for critique also allows us to dismantle ideas of textual coherence, and to inspire students to think critically about all texts. More importantly, though, it provides a segue into discussions about whiteness, about the privilege of the majority of mainstream students we teach, and about how racial categories are fragile precisely because whiteness claims invisible status, to cite Frankenberg,

[I]n examining whiteness ... one must recognize how continual processes of slippage, condensation, and displacement among the constructs "race", "nation", and "culture" continue to unmark white people while constantly marking and racializing others (Frankenberg, 1997, p. 6). 


\section{Children of the Sun as a pedagogical resource}

We frequently witness teaching and learning situations where white students voice their prejudice in what they understand to be a "safe" space; this follows the assumption that there are no Aboriginal students in the room because they cannot be visibly identified. Such assumptions can produce racist comments in the absence of appropriate teaching resources. In incorporating this knowledge from past practices into our teaching, we find the screening of Cbildren of the Sun particularly useful not only in deflecting the possibility of racist remarks, but also, in provoking consideration of comments that might have been made before they are uttered. The film's representation of Kia's light skin challenges assumptions that there are no Aboriginal students in the class, and teaches non-Indigenous students to reflect on pre-conceived notions of Aboriginal identity, to re-think them, to consider where they were learned, and to critique their validity. It also, importantly, following Frankenberg (1993), teaches them to interrogate their own whiteness, its perceived normality, and its invisibility as a racial or cultural signifier. The film, therefore, offers opportunities for students to reflect critically about racial and cultural difference represented in the consumption of texts and ideologies already learned by inciting dialogic responses to prior learning. Cbildren of the Sun also encourages students to absorb ideas of cultural difference through a text that characterises the production of urban Aboriginality in a context that both historicises and contemporises lived experience. As an Indigenous text, it introduces students to the politics inscribed in Indigenous self-representation.

In the first screening of the film, it was noted that many non-Indigenous students were confronted by the explicit critique of Christianity embedded in the narrative. Sensitive to many students' Christian values, we encouraged dialogue about this, and were able to use the film to demonstrate the discursive sanctioning of racism across a range of institutional sites. In confronting this issue, we were able to discuss with students the power of discourses of race, embedded in much Christian belief and reinforced in many institutions, without resorting to any denunciation of Christianity per se or any mockery of those who hold Christian beliefs. In practicing a non-confrontational standpoint that invites students to see Christianity as a discourse that accompanied and buttressed the project of colonisation, we were able to stimulate discussion that historicises the anger expressed by Aunty, and to bring to the fore anxieties about the issues, and instate a forum for productive debate that resists the impetus for students to "shut down" or feel threatened, while attempting to stimulate a reappraisal of these feelings. Various scenes in the film, we have found, encourage a Freirean approach to teaching and learning whereby students can consider their experiences and daily practices in a context that is both participatory and liberating, and from which they will learn and take on board other viewpoints (Freire, 1970). Freire's model is particularly useful in a developing pedagogy that requires delivery of content to a diverse student cohort, and particularly, one that is always underscored by the desire to implement Indigenous ways of knowing. Caught up in the current demands of the corporatisation of university, we are not immune to the "value" of overseas students, and, like many academics, are continually juggling content with often, a depoliticised student body that come to us with an expectation of learning about Aboriginality through the lens of current discourses of the "appeal" of traditional culture. Our task in teaching the notso-appealing aspects of history, and the ramifications of these on contemporary anxieties about identity, therefore, is continually re-evaluated, altered and updated, and relies significantly on visual texts that can impart narratives of cultural difference without watering down the politics of colonial histories or reducing our praxis to a populist pedagogical model.

The representation of light-skinned Aboriginal actors in Children of the Sun is a powerful tool; as mentioned, the bulk of our student cohort for our first year undergraduate course are students from the United States. As is the case with many domestic students, they are often confused by the challenge to their expectations of physical signs of Aboriginal identity. The film, through its subversion of these expectations is invaluable as a teaching resource and has on many occasions incited debate about skin colour, which, paradoxically, for reasons of "politeness", is often considered outside of the realm of appropriate discussion. In dismissing this notion, we make it clear that in fact, we are in the business of talking about colour although we recognise that this issue as it relates to urban Indigenous youth is not straightforward, simplistic or easy in theorising contemporary Indigenous identities. We also concede that the results of our efforts are not always positive or productive, and accept the limitations of one semester, which is the duration of most Study Abroad students. However, students who express a desire to return home and learn more of their own colonial histories are occasionally an inspiration, and particularly gratifying when considering the initial expectations of an "Aboriginal experience" that will include exposure to, or participation in "known" traditional cultural rituals. Children of the Sun, as a self-representational text, offers us a way of confronting racism through dialogue and through its youth focus; most of our students are young, and most are forthcoming in their own narratives of identity. Class dialogue is invariably productive, and always vibrant. We attribute this to a consciously non-confrontational approach that encourages personal narrative in the exploration 
of lived experience, a praxis grounded in efforts to produce participatory learning and to theorise ways of knowing from Indigenous standpoints.

Our reflections and student responses

In reflecting on our teaching of the film, we are able to see its strengths and shortcomings. In terms of the latter, the narrative tends to set up an untenable binary position between Christians (colonists) and Indigenous people which, although providing a point of connection and discussion for many Christian students that can be useful, can also be unnecessarily distracting in terms of the film's intended focus on selfrepresentation and identity. In relation to the film's pedagogical value, we note that it speaks to Indigenous and non-Indigenous students in very different ways; it represents for Indigenous students what many of them already know, as noted by one student who said he thought the film's value was "teaching whitefellas that being Aboriginal and being light-skinned can make life stressful". Another student stated that the film didn't really tell him anything he didn't know, and that he was "amazed to see how much discussion there was about something that was so familiar ..." In terms of the film's aims to emphasise the political force of self-representation, this is a heartening response. Indigenous students commented that they were able to associate on a personal level with the film as they know many of the actors, and were familiar with shots of local country. Many noted that the film's focus on identity and skin-colour is familiar and understood, and part of everyday experience, so easy to relate to. Many also commented on the fact that this is an Indigenous production, and therefore gives authority to Indigenous worldviews.

For non-Indigenous students who comprise the majority of our cohort, we are in agreement that the film contributes more in pedagogical terms to what they can learn, or unlearn. For example, many domestic students commented that the film inspired them to rethink what they had learned in high school about Indigenous people. One student noted that he had never thought about issues of colour before as this applies to Aboriginal people in urban contexts. Non-Indigenous students commented that: the film introduced them to an issue they had not previously thought much about; it inspired them to think about the pressures on Aboriginal kids to "pass", and the politics of passing, and in the case of American students, this was able to be discussed in the context of their culture. They also said that the history embedded into the narrative gave them a clearer understanding of the struggles experienced by contemporary Aboriginal kids. There was also evidence of resistance to the film's intended messages, although this came from only a couple of students in a cohort of over 40 where responses were anonymous.
變 Conclusion

Being Aboriginal for many contemporary youth can involve community participation, particular linguistic codes, the wearing of colours or paraphernalia that identify one as Aboriginal, association with Aboriginal organisations and so forth. It can take an imaginative form: the possibilities for construction and reconstruction take place alongside a changing set of histories that, for many Indigenous people, is fraught with the imposition of colonial rule, its regulative demands, its coercive strategies, and in many instances, consequential familial fracture and dislocation. Children of the Sun is underscored by the proposition that identity emanates from a desire to fit in somewhere, with something or with some identifiable group, for the purpose of belonging and feeling part of something familiar and safe. Children of the Sun illustrates the possibilities for identity that lie outside of available, stereotypical subject positions that construct urban Aboriginal youth largely according to perceptions of socio-economic class but at the same time, value communal affiliation and seek to reinstate identity caused by cultural fragmentation, and to explore possibilities for creating identities in a modern, urban and globalised context. The film explores what it is like for many urban Aboriginal youth to want to identify as Aboriginal, or to not want to, and what it is like to be fearsome of doing so, while offering opportunities through knowledge and dialogue for possibilities for creating and making available other subject positions that are relevant to lived experience in urban spaces, and the reconstruction of identities from the standpoint of agency and the shifting mechanisms of cultural pride. Importantly, though, as a resource that promotes critical pedagogy, Children of the Sun is a material example of the agency of local Aboriginal youth, and their courage and determination to be actively involved in, and engaged with the reconstruction of their identities.

\section{Acknowledgements}

We wish to thank the members of the Koori Youth Network Incorporated, Wollongong, New South Wales, and University of Wollongong students in ABST200 and ABST202 who contributed to subject evaluations.

\section{References}

Ang, I. (2001). On not speaking Chinese: Living between Asia and the West. London: Routledge.

Bhabha, H. K. (1998). The white stuff. Artforum International,360). Retrieved18 February, 2009, from http:/find.galegroup.com.ezproxy.uowedu.au/itx/start. do?prodid $=$ AONE

Boladeras, J. (2002) "It's easier to be black if you're black": Issues of Aboriginality for fair-complexioned Nyungar people. Unpublished MA thesis, Curtin University of Technology, Perth, Western Australia. 
children of the Sun. (2006). Directed by A. Loughlin, Merlin Films, 2006. Videocassette.

Davis, H. Y. (2004). Understanding Stuart Hall. London: Sage.

Frankenberg, R. (1993). The social construction of whiteness: White women, race matters. London: University of Minnesota Press.

Frankenberg, R. (Ed). (1997). Displacing wbiteness: Essays in social and cultural criticism. Duhram, NC: Duke University Press.

Freire, P. (1970). Pedagogy of the oppressed. New York, NY: Herder and Herder. Gilbert, K. (2002) [1973]. Because a white man'll never do it. Sydney, NSW: Harper Collins.

hooks, b. (1994). Teaching to transgress: Education as the practice of freedom. New York, NY: Routledge.

Moreton-Robinson, A. (2004). Whiteness, epistemology and Indigenous representation. In A. Moreton-Robinson (Ed.), Wbitening race: Essays in social and cultural criticism (pp. 75-88). Canberra, ACT: Aboriginal Studies Press.

Nakata, M. (1998). Anthropological texts and Indigenous standpoints. Australian Aboriginal Studies, 2:3-12.

Nakata, M. (2004). Ongoing conversations about Aboriginal and Torres Strait Islander research agendas and directions. The Ausiralian Joumal of Indigenous Education, 33, 1-6.

Nakata, M. (2007). Disciplining the sauages, savaging the disciplines. Canberra, ACT: Aboriginal Studies Press.

Perkins, M. (2004). False whiteness: "Passing" and the Stolen Generations. In A. Moreton-Robinson (Ed.), Whitening race: Essays in social and cultural criticism (pp. 164-175). Canberra, ACT: Aboriginal Studies Press.

Rudd, K. (2008). Full transcript of PM's speech. Retrieved 18 February, 2009 , from http:/wwwtheaustralian.news.com.au/story/0,25197,23207256 5013172,00 html

Yantpingu, M. (1994). Voices from the land. Sydney, NSW: ABC Books. 